\title{
A series of unfortunate events: Mind the windpipe
}

\author{
Anam Elarabi ${ }^{1}$, Mutaz Albakri ${ }^{1}$, Mona Babikir ${ }^{1}$, Mushtaq Ahmad $^{1}$, Rashid Mazhar ${ }^{1}$, and \\ Tasleem Raza ${ }^{1}$ \\ ${ }^{1}$ Hamad Medical Corporation
}

September 22, 2020

\begin{abstract}
Tracheal stenosis can be a disastrous consequence of prolonged endotracheal intubation. In the COVID-19 era, vigilance must be maintained not to overlook this complication.
\end{abstract}

\section{Case Description:}

A 55-year- old gentleman presented with respiratory symptoms and was diagnosed with severe Covid-19 pneumonia and ARDS requiring oxygen support the ended up needing endotracheal intubation and mechanical ventilation for 13 days after which he was extubated. Unfortunately, he was re-intubated 9 days later after his respiratory status suddenly deteriorated needing mechanical ventilation for another 5 days. Around 4 weeks after discharge he presented with shortness of breath and stridor with chest CT scan showing critical narrowing at the level of second thoracic vertebra (Figures 1-3). Surgical treatment with tracheal stenosis resection and anastomosis was done under general anesthesia and ECMO. He was discharged home 8 days later in good general condition. Vigilance must be maintained not to miss this serious complication especially in the era of Covid-19 pandemic.

\section{Key Clinical Message:}

Since we started to encounter post-covid pneumonia patients in our clinics, tracheo-laryngeal stenosis should be kept in mind as one of the complications post-prolonged intubation ( $>7$ days) particularly in those who are persistently symptomatic.

\section{Consent for publication}

This case report does not contain any personal identifier of the patient e.g. name, photograph, etc. It only includes radiological and pathological imaging.

A written patient informed consent of patient information, diagnostic images and publication was signed by the patient.

\section{Availability of data and material:}

The datasets used and/or analyzed during the current study are available from the corresponding author on reasonable request.

\section{Acknowledgements:}

We acknowledge the Qatar National Library for funding the open access publication of this article. We also acknowledge the Medical Research Center at Hamad Medical Corporation for their support.

Disclosure: The authors report no conflicts of interest in this work. 


\section{Authors contributions:}

Dr. Anam M. Elarabi, Corresponding author, manuscript review and submission

Dr. Mutaz M. Albakri. Co-author, manuscript writing, review and finalization.

Dr. Mona Babikir, Manuscript review.

Dr. Mushtaq Ahmed, Manuscript review.

Dr. Rashid Mazhar, Manuscript review.

Dr. Tasleem Raza, Manuscript review.

Figure 1: 3D reconstruction of CT-Chest showing the level and extent of the tracheal stenosis (Anterior view)

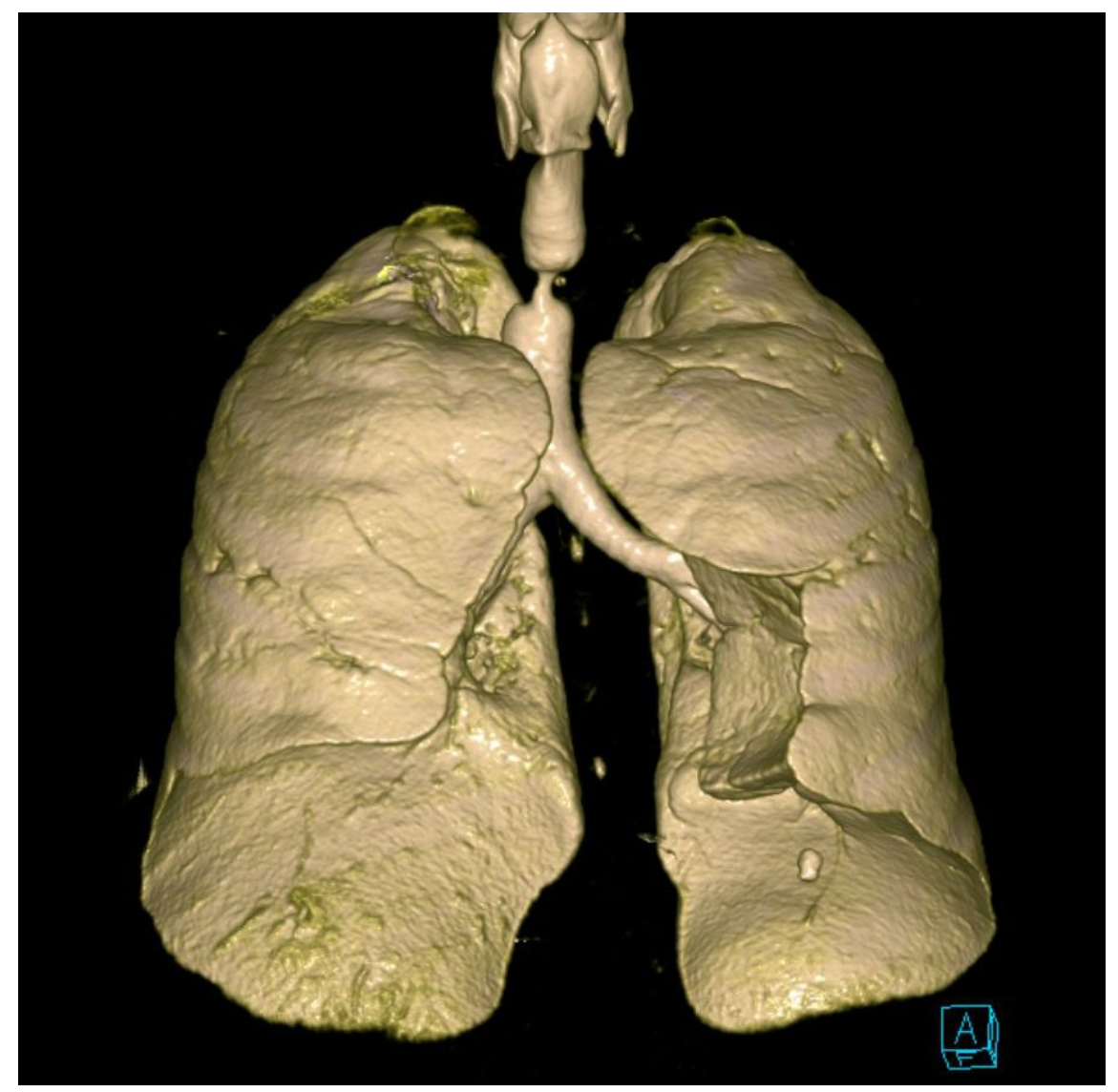

Figure 2: 3D reconstruction of CT-Chest showing the level and extent of the tracheal stenosis (Posterior view) 


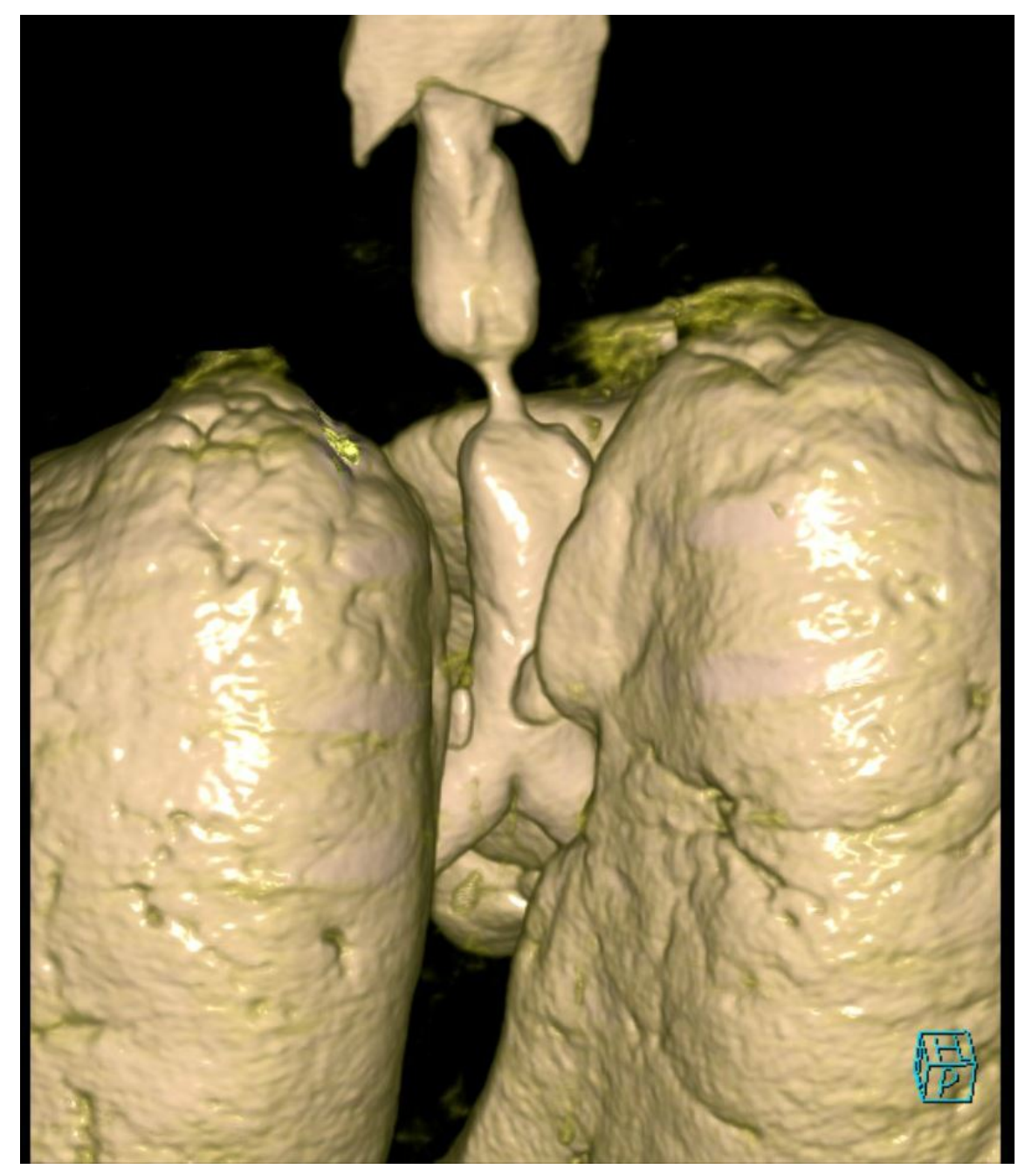

Figure 3: Saggital section of the CT-scan Chest showing the significant narrowing of the tracheal at the second thoracic vertebral level. 


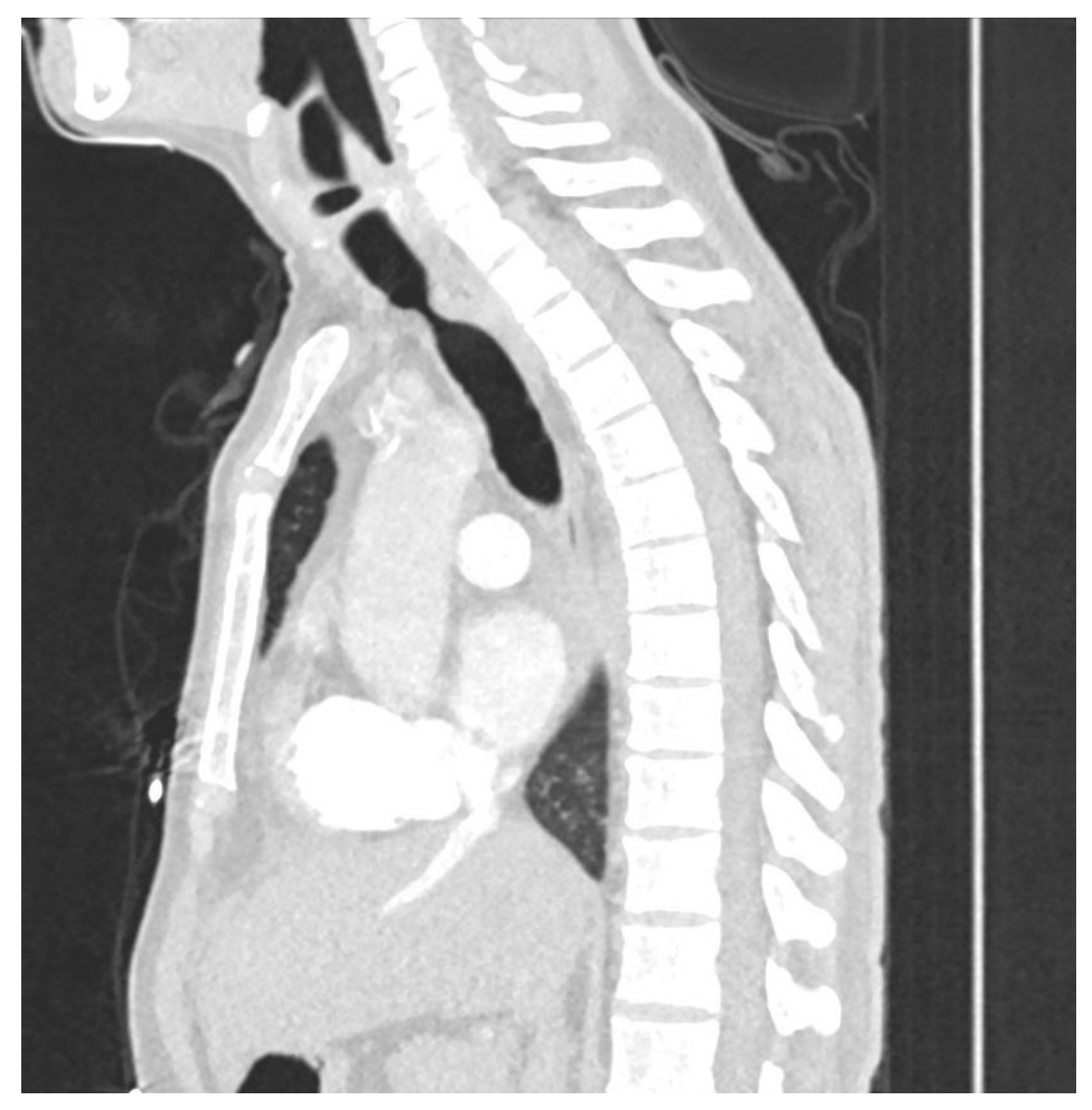




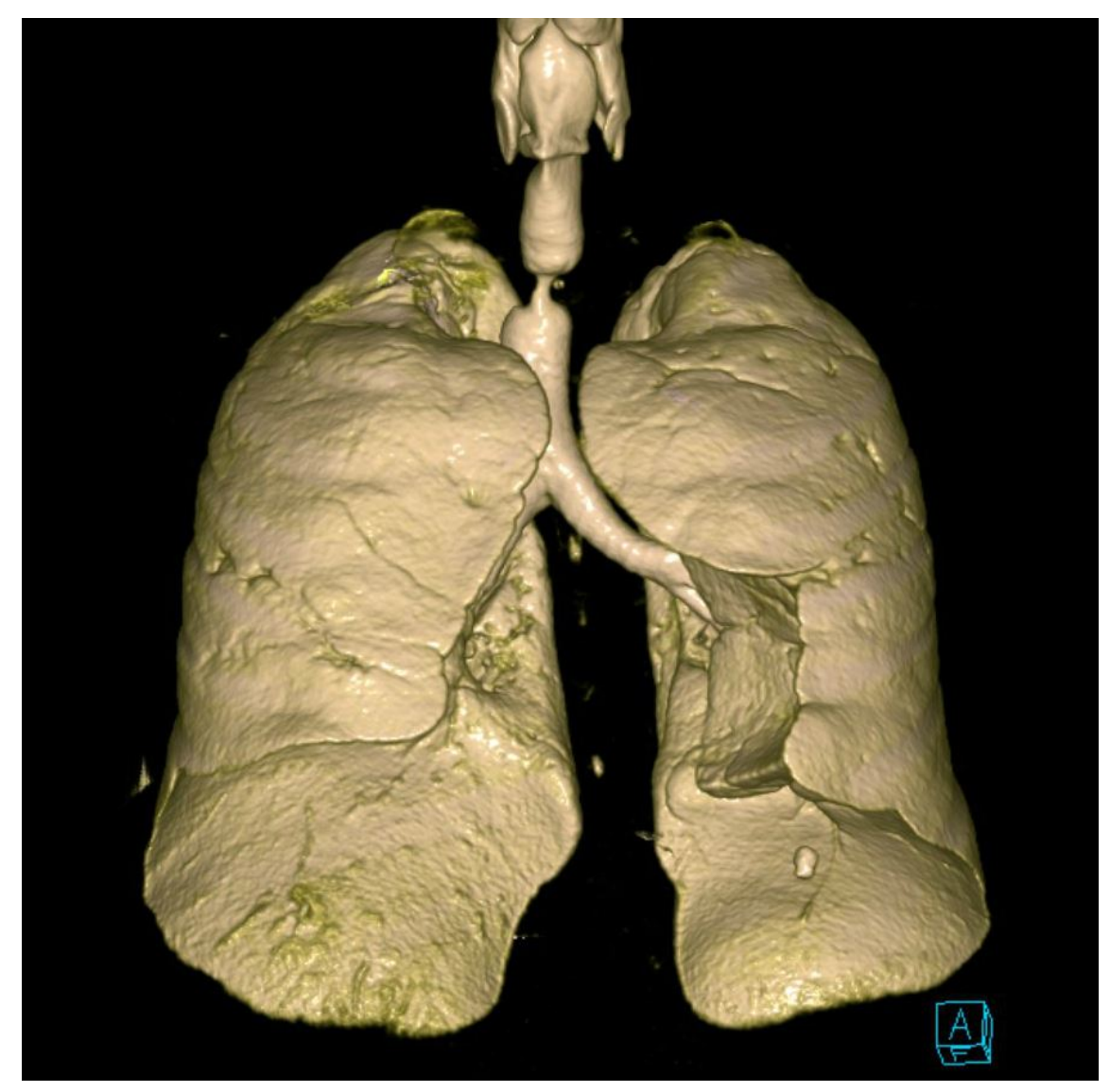




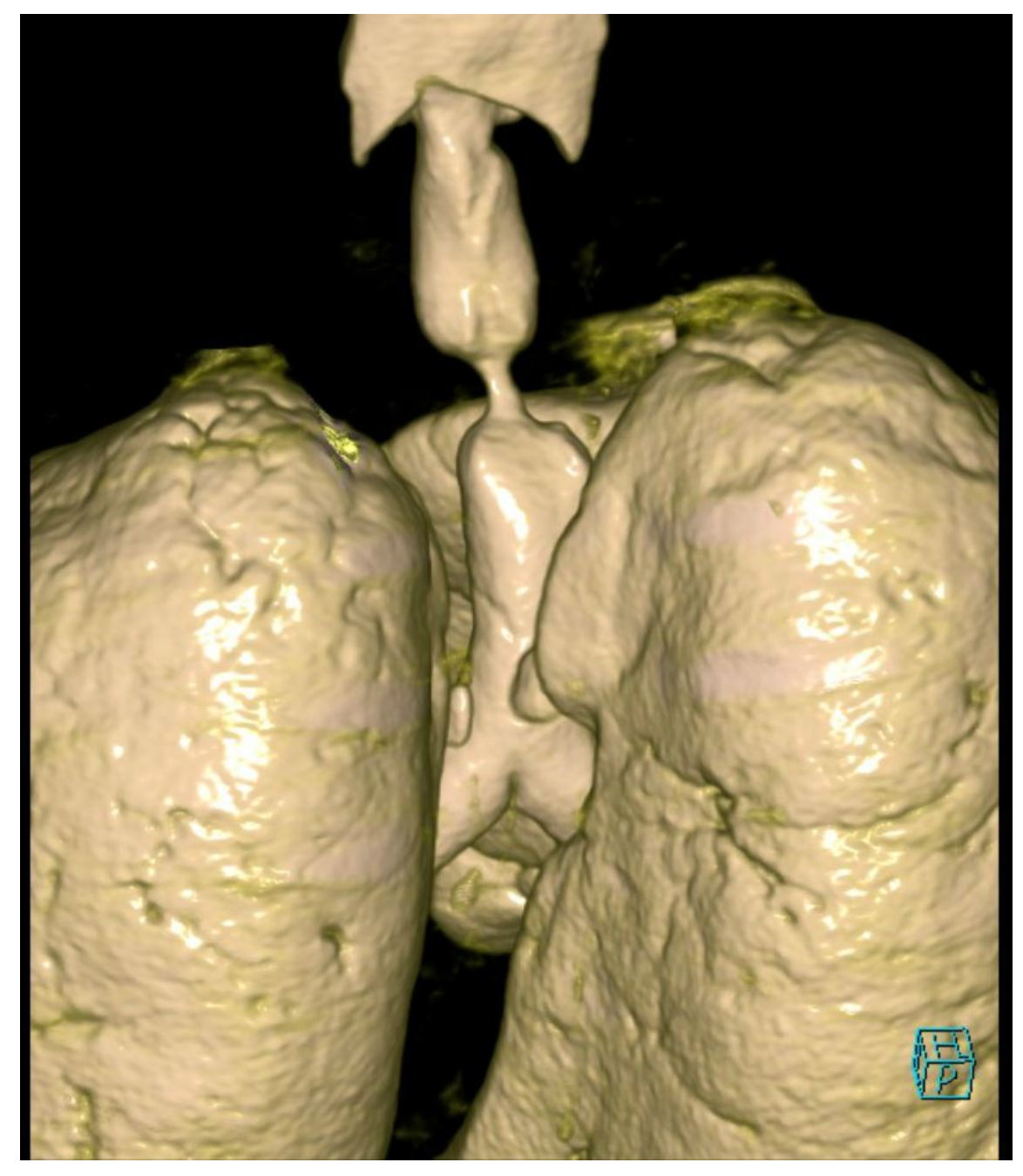




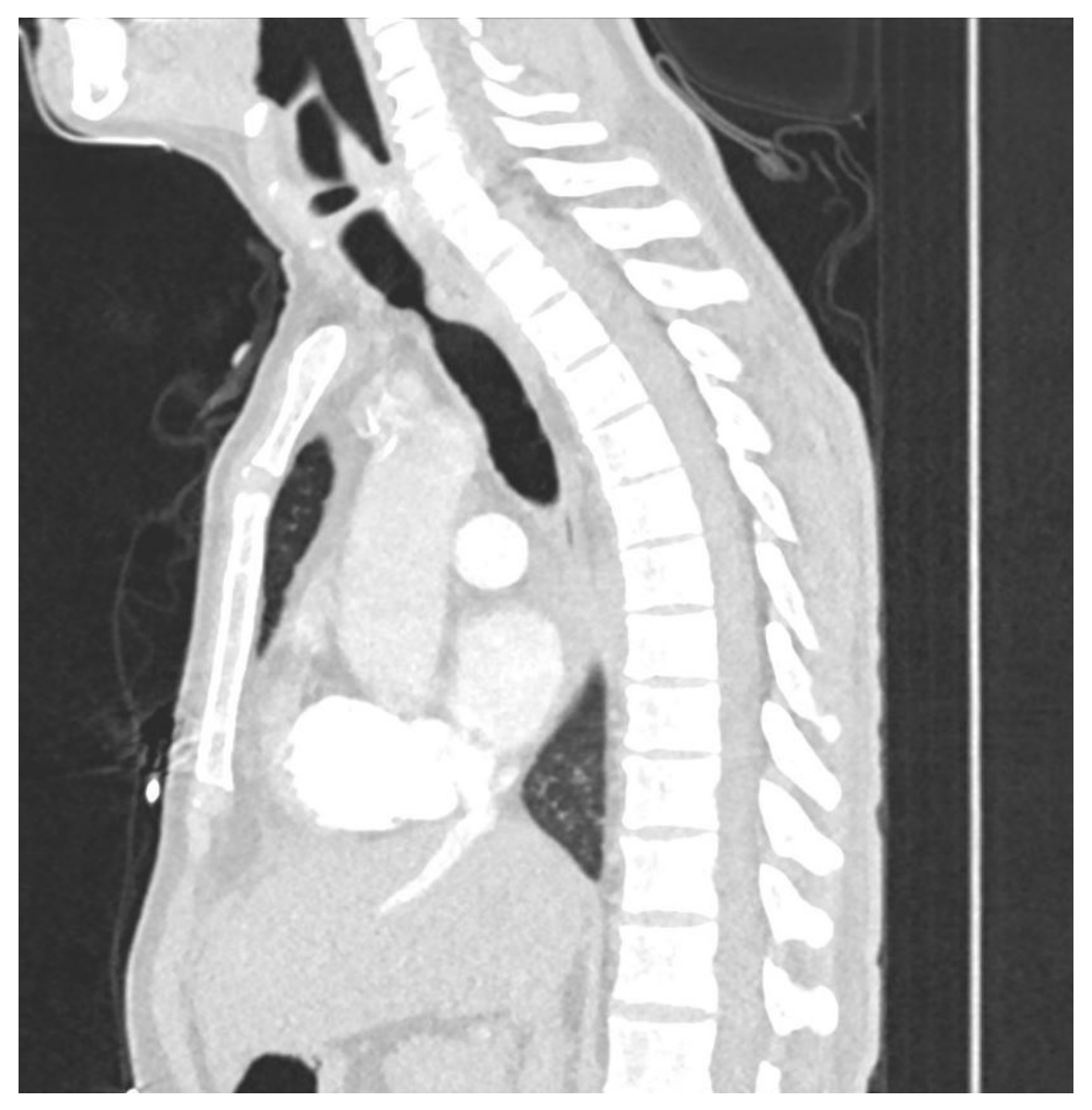

